\title{
"Resin Bonded Loop Connector Fixed Partial Denture - A Subtle Solution to Maintain Midline Diastema”
}

\author{
Khurshid Mattoo $^{1, *}$, Manas Singh ${ }^{2}$, Roma Goswami ${ }^{3}$ \\ ${ }^{1}$ Prosthodontics, College of dental sciences, Jazan University, KSA \\ ${ }^{2}$ Prosthodontics, Ideas dental college, Bareilly, Uttar Pradesh, India \\ ${ }^{3}$ Prosthodontics, Subharti dental college, Meerut, India \\ *Corresponding author: drkamattoo@rediffmail.com
}

Received November 22, 2014; Revised November 26, 2014; Accepted November 30, 2014

\begin{abstract}
Spacing between natural teeth is considered as a normal characteristic of class 1 malocclusion which is due to its high prevalence. However, spacing in the midline of the natural dentition has always been an area of interest for a prosthodontist. The challenge is so severe that most of the times its incorporation is part of treatment plan rather than any attempt to eliminate it, because midline diastema closure with a fixed prosthesis usually results in esthetic failures. With advances in dental cements especially resin cements; there has been an increase in delivery of resin bonded prosthesis, but has not been explored for possibility of maintaining midline diastema. This article presents a case of midline diastema successfully maintained by resin bonded prosthesis through the use of a loop connector between the pontic and the retainer.
\end{abstract}

Keywords: connector, occlusion, enamel, resin cement, labial frenum

Cite This Article: Khurshid Mattoo, Manas Singh, and Roma Goswami, "Resin Bonded Loop Connector Fixed Partial Denture - A Subtle Solution to Maintain Midline Diastema.” International Journal of Dental Sciences and Research, vol. 2, no. 6 (2014): 168-170. doi: 10.12691/ijdsr-2-6-12.

\section{Introduction}

Spacing between natural teeth is a result of a discrepancy between the size of the bony arch and the mesiodistal size of natural teeth. Spacing may be generalized or localized and is considered as part of malocclusion. Midline diastema is a clinical condition that presents itself as a space between natural teeth in the midline either in the maxilla or the mandible or both. When the space is less, it may add to the esthetic value of a human face, but when the space is more, patients usually want a solution to make it disappear. For a prosthodontist who has to decide between eliminating space and natural look, most of the times the space is left as such because elimination of space results in increased mesiodistal size of the restoration on adjacent teeth. Although many approaches have been made the use of loop connector in such cases is unavoidable as it yields most appropriate results.

Advances in dental cements in the last decade or so have also seen the rise of resin bonded bridges as a mean of alternative yet conservative replacement for conventional fixed partial denture. The clinical performance of resin bonded bridges has been reported with success [1-5] as well as failures [6,7] a resin bonded prosthesis relies on the retention generated by resin cement tags through different methods like etching, perforation, micro or macro mechanical and even chemical. [8-11] This article describes a unique and rare management of midline diastema case that was creating hurdle in conservative management of a Kennedy class 3 partial edentulous situation with fixed partial denture. The case was successfully managed by utilizing the principle advantages of both resin bonded and a loop connector fixed partial denture.

\section{Clinical Case Report}

A male patient in his early forties was referred by department of oral medicine and radiology to the department of Prosthodontics for an opinion regarding restoration of the maxillary edentulous area with a fixed prosthesis.

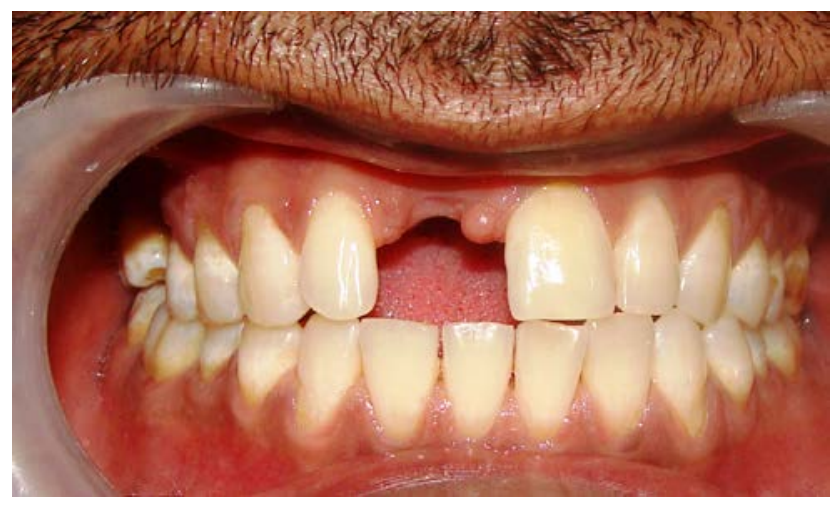

Figure 1. Intra oral view showing labially placed incisive papilla, wide edentulous space and buccally inclined maxillary right first molar 


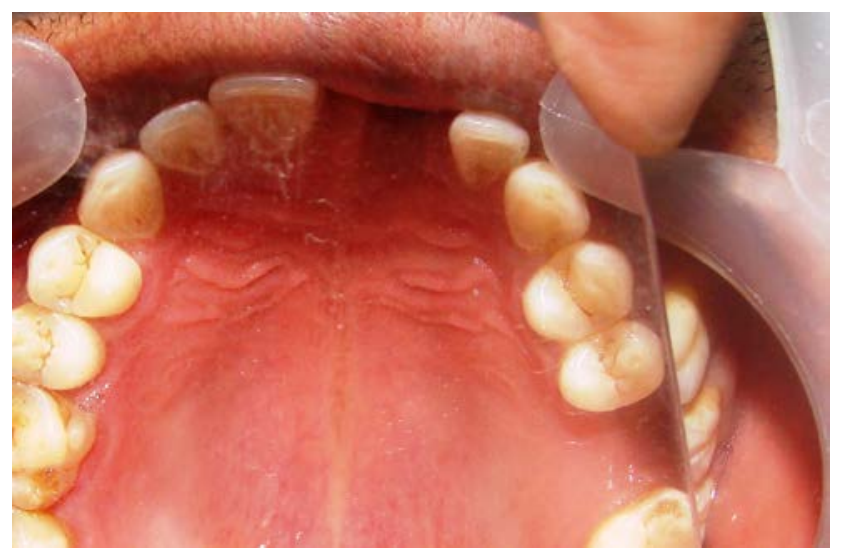

Figure 2. Occlusal view of maxillary missing right central incisor and its relation to arch form

Patients medical, social and drug history were nonsignificant, whereas dental history revealed loss of maxillary right central incisor and maxillary right first molar due to trauma and caries respectively. Extra oral examination showed normal features whereas intra oral examination revealed buccally placed maxillary right second molar and labially place incisive papilla. Features of a characteristic midline diastema with non-coincidence of maxillary and mandibular midlines were evident from functional examination of the occlusion (Figure 1 and Figure 2). After diagnostic mounting and mock up analysis a treatment plan was presented to him that included a resin bonded retained fixed partial denture connected by a loop to mimic the lost midline diastema.

The treatment started with preliminary impression making with Irreversible hydrocolloid (CA 37; Cavex, Haarlem, Holland), following which diagnostic casts were mounted and a design for the final resin bonded prosthesis was made along with radiographic interpretation of amount of enamel present. Abutment teeth (maxillary right central incisor and left lateral incisor) were prepared only on the palatal aspect of the crowns with preparation being present in the enamel. Final impressions were made with Addition polyvinyl siloxane material (Reprosil, Dentsply/Caulk; Milford, DE, USA) and temporization was done in the form of bonding agent application. To maintain the distance between the two central incisors a loop connector was designed that would replicate midline diastema in the restoration. The cast framework was tried in the patient and porcelain was later fired to act as a single standing pontic. Additional gingival porcelain was added to compensate for the bony loss under the pontic. The retainers connecting the pontic with a loop connected were then bonded using resin cement (Super Bond, C\&BMetabond, Parkell, Inc. U.S.A) (Figure 3). After restoring the anterior guidance the posterior edentulous span was restored with a three unit fixed fixed partial denture prosthesis (Figure 4). The patient was then given instructions regarding the oral hygiene maintenance and was put on strict follow up.

\section{Discussion}

Although implant supported single crowns are the choice of treatment in patients presenting with Kennedy class 3 partial edentulous situation, [12] there are many patients who cannot undergo such treatment. [13] Resin bonded prosthesis has evolved since Rochette described the first version for splinting of the periodontally involved teeth. [14] Since then the resin bonded designs as well as the cement used has evolved and has become a reliable prosthetic option for restoration of missing single standing teeth provided occlusion is favorable. Higher strength of resin cements have also allowed resin bonded to be used with multiple loop connectors. [15,16,17] The design selected in this case too was largely due to the presence of a favorable occlusion. Clinical evaluation of occlusion when designing such prosthesis should exclude the presence of excursive contacts at the margins of the retainer with the tooth. If a protrusive contact is present, then the excursive movement will unseat the retainers irrespective of the strength of the cement. The advantages associated with the prosthesis mentioned include natural esthetic effect, ease in hygiene maintenance and conservation of tooth structure. The disadvantage is in the form of a loop connector that the patient finds initially as annoying because of the bulk, but with time the tongue adapts to its presence. In some cases where the connector is thick the patient's phonetics are affected.

\section{Conclusion}

Within the scope of this article, resin bonded loop connector prosthesis is an innovative treatment option that needs to be added in the armory of fixed Prosthodontics. More patients treated with the indicated prosthesis would allow to study its long term survival in oral cavity as an alternative to other prosthetic options.

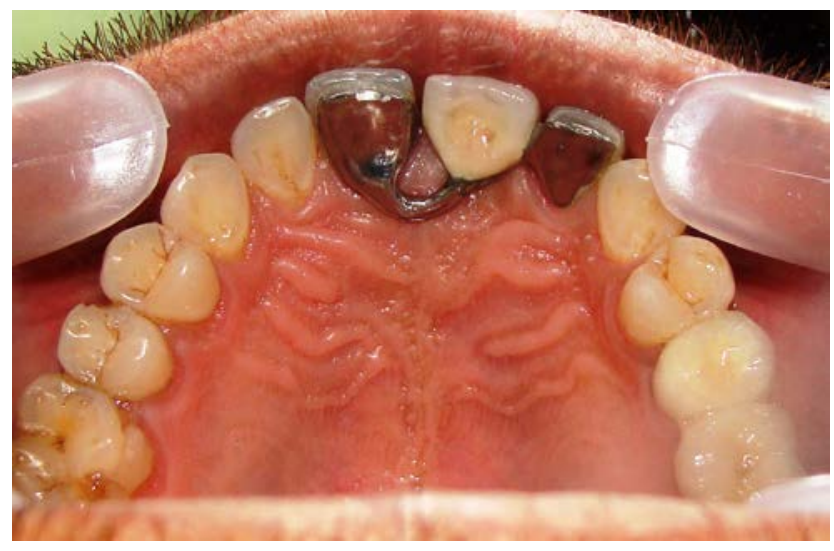

Figure 3. resin bonded retainers connecting the pontic to the retainer on right maxillary central incisor with a loop connector

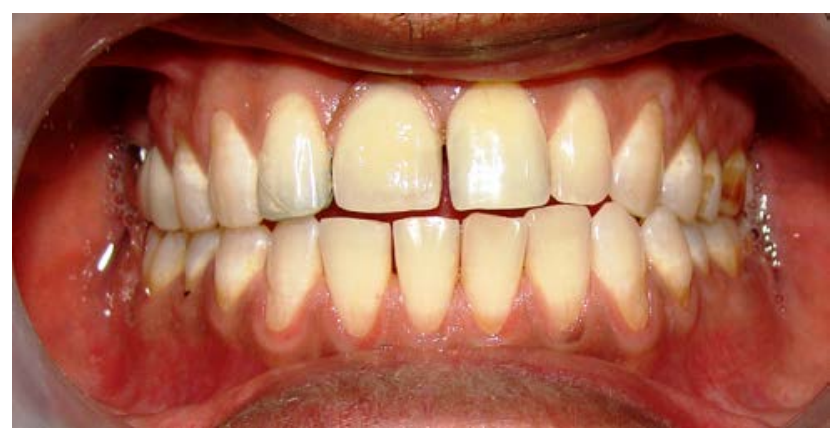

Figure 4. Frontal view of the maxillary arch showing the resin bonded loop connector retaining the midline diastema. Note the open bite and correction of maxillary right first molar 


\section{References}

[1] Creugers NHJ, Snoek PA, Van't Hof MA, Kayser AF. Clinical performance of resin-bonded bridges, a 5 year prospective study. Part I: Design of the study and influence of experimental variables. J Oral Rehabil 1989; 16: 427-436.

[2] Creugers NHJ, Snoek PA, Van’t Hof MA, Kayser AF. Clinical performance of resin-bonded bridges, a 5 year prospective study. Part II: Influence of patient dependent variables. J Oral Rehabil 1989; 16: 521-527.

[3] Barrack G, Bretz WA. A long-term prospective study of the etched-cast restoration. Int J Prosthodont 1993; 6: 428-434.

[4] Dunne SM, Millar BJ. A longitudinal study of the clinical performance of resin bonded bridges and splints. Br Dent J 1993; 174: 405-411.

[5] Priest G. An 11-year reevaluation of resin-bonded fixed partial dentures. Int J Periodontics Restorative Dent 1995; 15: 239-247.

[6] Thompson VP, Wood M, De Rijk W. Bonded bridges recalls and Weibull distribution; results averaging seven years. J Dent Res 1989; 68: 427.

[7] Clyde JS, Boyd T. The etched cast metal resin-bonded (Maryland) bridge: a clinical review. J Dent 1988; 16: 22-26.

[8] Howe DF, Denehy GE. Anterior fixed partial dentures utilizing the acid-etch technique and a cast metal framework. J Prosthet Dent 1977; 37: 28-31.

[9] St George G, Hemmings K, Patel K. Resin-retained bridges revisited. Part 1. History and indications. Prim Dent Care 2002; 9: 87-91.
[10] Edelhoff D, Sorensen J A. Tooth structure removal associated with various preparation designs for anterior teeth. J Prosthet Dent 2002; 87: 503-509.

[11] Pjetursson BE, Tan W C, Tan K, Bragger U, Zwahlen M, Lang NP. A systematic review of the survival and complication rates of resin-bonded bridges after an observation period of at least 5 years Clin Oral Implants Res 2008; 19: 131-141.

[12] Pjetursson BE, Bragger U, Lang NP, Zwahlen M. Comparison of survival and complication rates of tooth-supported fixed dental prostheses (FDPs) and implant-supported FDPs and single crowns (SCs). Clin Oral Implants Res 2007; 18 Suppl 3: 97-113.

[13] Jung RE, Pjetursson BE, Glauser R, Zembic A, Zwahlen M, Lang NP. A systematic review of the 5-year survival and complication rates of implant supported single crowns. Clin Oral Implants Res 2008; 19: 119-130.

[14] Hussey D L, Wilson N H. The provision of resin-bonded bridgework within the General Dental Services 1987-1997. Prim Dent Care 1999; 6: 21-24.

[15] Kalra A, Gowda ME, Verma K. Aesthetic rehabilitation with multiple loop connectors. Contemp Clin Dent 2013; 4: 112-5.

[16] Akulwar R et al. Oral Rehabilitation with Multiple Loop Connectors-A Case Report. Indian Journal of Applied Research 2014: 4 (5): 512-514

[17] Shah M et al. Aesthetic Triad: Maryland Bridge, Ovate Pontic and Loop Connector: A Case Report. Journal of Dental Sciences \& Oral Rehabilitation, Oct-Dec 2012: 45-47. 